\title{
Recombination-Induced Suppression of Cell Division Following P1-Mediated Generalized Transduction in Klebsiella aerogenes
}

\author{
Robert A. Bender ${ }^{1}$ and Lidia C. Sambucetti ${ }^{2}$ \\ ${ }^{1}$ Department of Cellular and Molecular Biology, Division of Biological Sciences, University of Michigan, Ann Arbor, MI 48109, USA \\ ${ }^{2}$ Department of Molecular Biology, Albert Einstein College of Medicine, Bronx, NY 10461, USA
}

\begin{abstract}
Summary. Klebsiella aerogenes recombinants resulting from bacteriophage $\mathrm{P} 1$-mediated generalized transduction failed to increase in number for approximately six generations after transduction. Nevertheless these recombinants continued to grow and became sensitive to penicillin after a transient resistance, suggesting that the cells were growing as long, non-dividing filaments. When filamentous cells were isolated from transduced cultures by gradient centrifugation, recombinants were 1000-fold more frequent among the filaments than among the normal-sized cells. The suppression of cell-division lasted for six generations whether markers near the origin ( $g l n, i l v$ ) or terminus (his, trp) of chromosome replication were used, despite a 50 -fold difference in transduction frequencies for these markers. The suppression of cell division was a host response to recombination rather than to P1 invasion since cells lysogenized by P1 in these same experiments showed only a short (two generation) suppression of cell division. We speculate that the suppression of cell-division is an SOS response triggered by the degraded DNA not incorporated in the final recombinant. We demonstrate that both the filamentation and the transient penicillin resistance of recombinant cells can be exploited to enrich greatly for recombinants, raising transduction frequencies to as high as $10^{-3}$.
\end{abstract}

\section{Introduction}

Bacteriophage P1 mediated generalized transduction is one of the most widely used and trusted techniques in studying the genetics of Escherichia coli (Bachman and Low 1980). The utility of $\mathrm{P} 1$ was further increased when a simple method for isolating P1-sensitive derivatives of many enteric bacteria was described (Goldberg et al. 1974). During studies of the glnA region of the Klebsiella aerogenes chromosome, (Streicher et al. 1975) several anomalous results arising from P1 mediated transduction led us to investigate the process of recombination further. These investigations indicate that recombination following P1 mediated transduction, caused a prolonged suppression of cell division in enteric bacteria.

The mechanism of P1-mediated generalized transduction has been studied in many laboratories since its first characterization by Lennox (1955). The process can be divided into three stages: the generation of transducing par-

Offprint requests and all correspondence to: $\mathrm{R}$.A. Bender ticles (Ikeda and Tomizawa 1965; Harriman 1972) the recombination of some portion of a transducing particle with the homologous region of a bacterial chromosome (Sandri and Berger 1980; Newman and Masters 1980) and the biological effects of the recombination event on the recombinant cell. This last stage is the focus for this work.

\section{Materials and Methods}

Bacterial and Phage Strains. Bacterial strains in this study are derived from $K$. aerogenes strain W70 (MacPhee et al. 1969) and were made sensitive to phage P1 by either of two methods (Goldberg et al. 1974; Goldberg and Magasanik 1975). Strains MK9000 (prototroph), MK9011 (glnA6, ilvA1), and MK9282 ( $\ln A 20$, rha-2) have been described previously (Streicher et al. 1975). Strain MK9541 ( $\ln A 6$, ilvA1, his-3, trp-3) was derived from MK9011 following mutagenesis with ethylmethane sulfonate. Bacteriophage P1 is P1 clr100 Km described previously (Goldberg et al. 1974). Growth of bacteria was at $30^{\circ} \mathrm{C}$ in LB gln medium (Bender et al. 1975). Phage growth has been described (Goldberg et al. 1974). K. aerogenes was used for these experiments because the yield of transductants per plaque-forming-unit is about ten-fold higher with $K$. aerogenes lysates than with $E$. coli, allowing recovery of sufficient transductants even when the multiplicity of infection must be kept low.

Transductions. Bacteria were grown to late exponential phase (about $5 \times 10^{8} / \mathrm{ml}$ ) in broth (LB gln) and concentrated 10 -fold by centrifugation and resuspension in broth supplemented with $5 \mathrm{mM} \mathrm{CaCl}$. Phage were added to a final ratio of about 0.5 or 5 plaque forming units per cell (strains MK9282 or MK9541 respectively). After allowing adsorption at $30^{\circ} \mathrm{C}$ for $20 \mathrm{~min}$, the mixture was either plated directly on selective medium to assay for transductants or else it was diluted to about $1.5 \times 10^{7} / \mathrm{ml}$ in prewarmed broth and allowed to grow with vigorous aeration at $30^{\circ} \mathrm{C}$. Adsorption was not monitored in the experiments shown in Fig. 1-5, but in similar experiments adsorption was about $10 \%$ and $1 \%$ for strains MK9282 and MK9541 respectively; thus the actual multiplicity of infection was well below 1. Selective medium for recombinants was $\mathrm{W}$ salts (Bender et al. 1975) supplemented with $0.4 \%$ glucose $(\mathrm{w} / \mathrm{v})$ and $0.2 \%(\mathrm{w} / \mathrm{v})$ ammonium sulfate, and where appropriate, glutamine, isoleucine, tryptophan, and histidine. Specialized transductants were selected on broth plates to which kanamycin, at $50 \mu \mathrm{g} / \mathrm{ml}$, was added. 
Sucrose Gradient Centrifugation. Sucrose gradients containing $10-35 \%(\mathrm{w} / \mathrm{v})$ sterile sucrose over a cushion of $60 \%$ $(w / v)$ sucrose were prepared in nitrocellulose tubes. About $10^{10}$ cells were layered on top in a volume of $0.5 \mathrm{ml}$ and the tubes were placed in a Sorval GLC-2B or Beckman TJ-6 centrifuge and subjected to centrifugation at $1000 \mathrm{xg}$ for $10 \mathrm{~min}$ at room temperature. The bottom of the tube was pierced with a sterile needle and fractions of $0.2-1.0 \mathrm{ml}$ were collected and assayed for total viable cells and for transductants. The concentration of sucrose in each fraction was determined by the refractive index.

\section{Results}

\section{Cell Division is Suppressed After Transduction}

Phage grown on the prototrophic strain MK9000 were mixed with cells of the glutamine auxotroph, strain MK9282 $(g \ln A 20)$, and this transduction mixture was diluted into broth and allowed to grow in exponential phase for $10 \mathrm{~h}$. Samples were taken at intervals and the growth of the $\mathrm{Gln}^{+}$transductants was compared with the growth of the untransduced cells. The data in Fig. 1 show that the $\mathrm{Gln}^{+}$transductants do not increase in number for $3.5 \mathrm{~h}$ and then their growth exactly parallels that of the culture as a whole. The 30-35-min doubling time observed for the culture as a whole from time zero, and the $\mathrm{Gln}^{+}$transductants after $3.5 \mathrm{~h}$, is characteristic of $K$. aerogenes growing in broth at $30^{\circ} \mathrm{C}$ and so demonstrates that the manipulation of the culture during the adsorption of phage did not affect the bulk of the cells, but rather led to a specific effect on the transductants.

\section{Phage Adsorption and DNA Injection do Not Cause Suppres- sion of Cell Division}

The transducing phage used in these experiments is P1 clr100Km (Goldberg et al. 1975) which confers resistance to the antiobiotic kanamycin on cells lysogenic for the phage. The P1 prophage is maintained as a plasmid, therefore the formation of lysogens requires phage adsorption and DNA injection, as does generalized transduction, but lysogen formation does not involve a recombinational event with the chromosome, the key event in generalized transduction (Ikeda and Tomizawa 1965). The data in Fig. 1 show that the lysogenized (kanamycin-resistant) cells display only a brief lag of about $1-1.5 \mathrm{~h}$ before they begin increasing in number at the log-phase rate of the rest of the culture. Thus the physical events involved in getting transducing DNA into cells (adsorption and injection) cannot explain the long lag in cell division for the Gln ${ }^{+}$ transductants.

\section{Transductants Grow But do Not Divide}

If the $\mathrm{Gln}^{+}$transductants were growing but not dividing they would be sensitive to penicillin, which lyses actively growing cells. Therefore strain MK9282 ( $\ln A 20)$ was transduced with P1 grown on MK9000 and diluted into prewarmed broth containing penicillin. As can be seen in Fig. 2, the culture as a whole is immediately sensitive to penicillin, confirming that growth begins immediately upon dilution. The $\mathrm{Gln}^{+}$transductants are transiently resistant to penicillin (about $30 \mathrm{~min}$ ) but then become as sensitive to penicillin as the bulk of the culture.

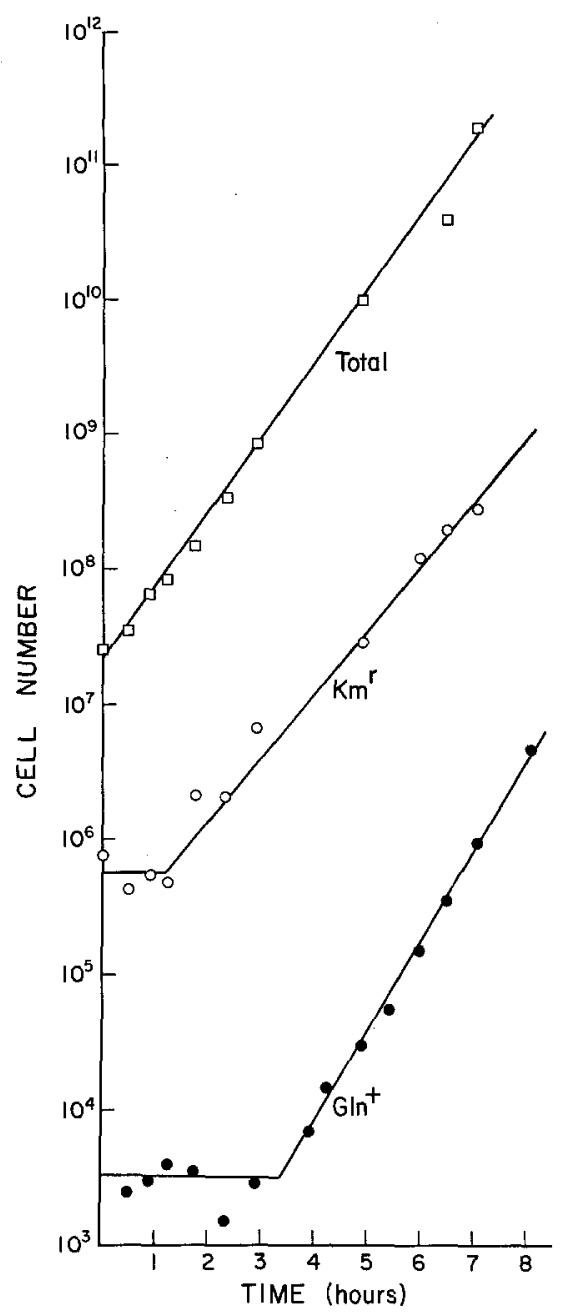

Fig. 1. The kinetics of growth following transduction. Phage P1 grown on the prototrophic strain MK9000 was adsorbed to cells of strain MK.9282 $\left(\mathrm{Gln}^{-}\right)$as described in Materials and Methods. The entire mixture was diluted to $10^{7}$ cells $/ \mathrm{ml}$ and allowed to grow at $30^{\circ} \mathrm{C}$ with vigorous aeration and periodic dilution to maintain $\log$ phase growth. Samples were withdrawn periodically and titred for transductants (on minimal medium lacking glutamine), for lysogens (on broth plates supplemented with kanamycin), and for total viable cells (on broth plates). The first time point was plated immediately before the dilution and all titres are expressed relative to the initial dilution. $\mathrm{Gln}^{+}(\bullet)$, lysogens (o), total viable cells (a). The slightly faster growth of the Gln ${ }^{+}$transductants is characteristic of this strain where even $0.2 \%$ glutamine is insufficient to allow maximum growth rate of the glutamine auxotroph (data not shown)

The data in Fig. 1 show that transductants did not increase in number before $3.5 \mathrm{~h}$ while the data in Fig. 2 show that the transductants grew at an apparently normal rate after a brief lag. Taken together, these two observations suggest that the transductants were filamenting. To test directly for filamentation, we analyzed the transduced cultures by sucrose gradient centrifugation. Strain MK9282 $(g \ln A 20)$ was transduced with P1 grown on MK9000, diluted into broth, and allowed to grow at densities less than $10^{9} / \mathrm{ml}$ for $3 \mathrm{~h}$. The cells were then sedimented through a sucrose gradient and the fractions were assayed for viable cells and $\mathrm{Gln}^{+}$. Figure $3 \mathrm{a}$ shows that a fast sedimenting fraction containing a very small portion of the population contains a substantial portion of the transductants. When 


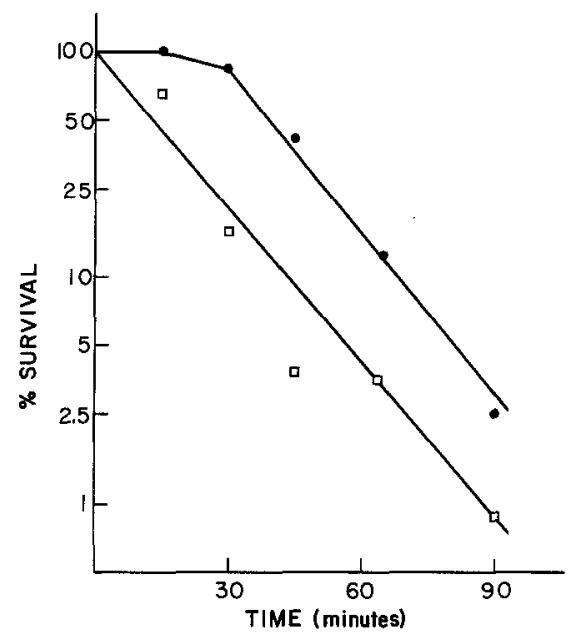

Fig. 2. Sensitivity of transductants to penicillin. Phage P1 grown on the prototrophic strain MK 9000 was adsorbed to strain MK9282 $(g \ln A 20)$ as described in Materials and Methods. The adsorption mixture was diluted to $1 \times 10^{7}$ cells $/ \mathrm{ml}$ into prewarmed broth supplemented with 5000 units $/ \mathrm{ml}$ of penicillin G. Samples were withdrawn periodically and titred for $\mathrm{Gln}^{+}$transductants $(\bullet)$ and for total viable cells ( $\square$ ). Values are expressed relative to initial values

the transductant frequency $\left(\mathrm{Gln}^{+} /\right.$total cells) is calculated for the various fractions (Fig. $3 \mathrm{~b}$ ) the frequency of transductants among the fast-sedimenting cells was found to be at least $10^{-3}$. This value is to be compared with the value of $6 \times 10^{-6}$ for the fractions containing the majority $(65 \%)$ of the viable cells. The peak of $\mathrm{Gln}^{+}$transductants clearly sediments faster than the bulk of the cells (corresponding to a shoulder on the whole cell count) and the fastest-sedimenting cells are greatly enriched for $\mathrm{Gln}^{+}$transductants. When this fastest-sedimenting peak was viewed with the phase contrast microscope, it consisted almost exclusively of long filamentous cells (not shown).

In an analogous experiment the transduction mixture was applied to the sucrose gradient immediately after adsorption with no time allowed for growth except that which may have occurred in the adsorption mixture. The $\mathrm{Gln}^{+}$ transductants again sedimented in two peaks. In the fast moving shoulder the transduction frequency was as high as $5 \times 10^{-3}$, suggesting that virtually every cell in the viable count shoulder was transduced for some gene or other.

One further observation can be made by comparing the experiments shown in Figs. $3 \mathrm{a}$ and $4 \mathrm{a}$. At $\mathrm{t}=0$, the $\mathrm{Km}^{\mathrm{R}}$ (lysogenic) cells cosedimented with the $\mathrm{Gln}^{+}$transductants while at $\mathrm{t}=3$ hours the $\mathrm{Km}^{\mathrm{R}}$ (lysogenic) cells cosedimented with the bulk $\left(\mathrm{Gln}^{-}\right)$of the cells (data not shown). This suggests that the $\mathrm{Km}^{\mathrm{R}}$ cells lag only briefly, and are dividing at the normal rate well before $t=3$ hours (Fig. 1).

\section{Length of Cell-Division Lag is Marker Independent}

Fast-growing enteric bacteria have several replication forks traversing their chromosome at any one time, resulting in a large number of copies of genes near the origin of replication and a much reduced number of copies of genes near the terminus of replication (Cooper and Helmstetter 1968). Since $\operatorname{gln} A$ lies near the origin of replication (Streicher et al. 1975; Zyskind et al. 1981) the time before $\mathrm{Gln}^{+}$cells begin to increase in number might have reflected the time required
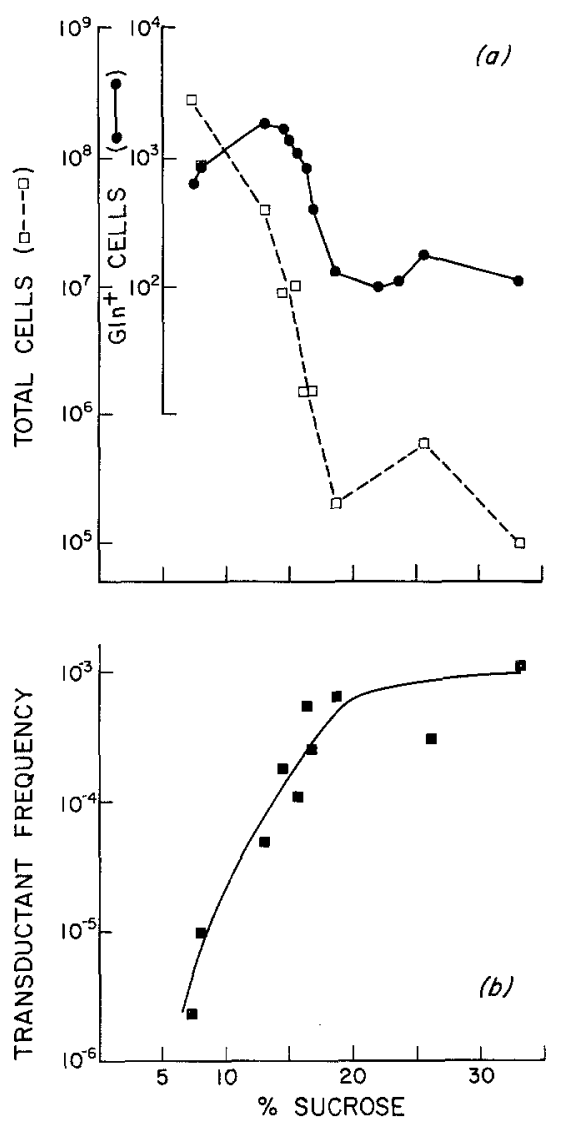

Fig. 3a, b. Separation of recombinant and non-recombinant cells by sucrose velocity gradient centrifugation. Phage grown on the prototrophic strain MK9000 were used to transduce strain MK9282 to $\mathrm{Gln}^{+}$as described in Materials and Methods. After adsorption, the cells were diluted into fresh broth and allowed to grow at $30^{\circ} \mathrm{C}$ with vigorous aeration with $\log$ phase growth maintained by periodic dilutions. After $3 \mathrm{~h}$ of growth, the cells were concentrated by centrifugation and $10^{10}$ cells were applied to a $10-30 \%$ sucrose gradient. After centrifugation and collection as described in Materials and Methods, the fractions were titred for $\mathrm{Gln}^{+}$recombinants, for kanamycin-resistant lysogens, and for total viable cells. The refractive index of each fraction was also measured to determine the sucrose concentration. a Gln ${ }^{+}$transductants $(\bullet)$; total viable cells $(\square)$. b Transduction frequency, calculated as the ratio of $\mathrm{Gln}^{+}$to total viable cells

for segregation of the multiple copies of the $g \ln A 20$ allele. If segregation were the explanation for the lag seen in Fig. 1, then there should be a strict marker dependence with originproximal markers like $g \ln A$ and $i l v A$ showing longer lags and terminus-proximal markers like trp and his showing little or no lag. When phage grown on the prototropic strain MK9000 were used to transduce the multiply auxotrophic strain MK9541 ( $g \ln A$, ilvA, trp, his), transductants again failed to increase in number for about $3.5 \mathrm{~h}$. Moreover, the length of the lag was the same for all four markers. The data for the Gln ${ }^{+}$and $\operatorname{Trp}^{+}$transductants are shown in Fig. 5. With this strain, MK9541, as with strain MK9282, the culture as a whole grew without a lag upon dilution and the lysogens began dividing after a brief lag of 1-1.5 h (compare Fig. 1 and Fig. 5).

To show that the length of the lag was the same for all four loci, we compared the relative transduction frequencies at $\mathrm{t}=0$ (before dilution) and late in the experiment 

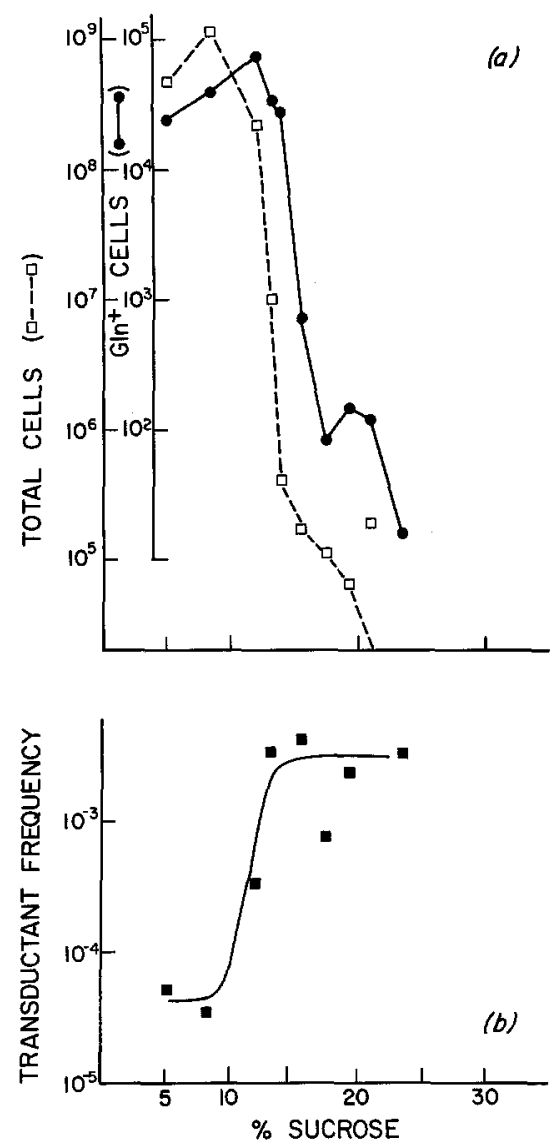

Fig. 4 a, b. The same experiment as Fig. 3 except that the cells were subjected to sucrose gradient centrifugation immediately after adsorption at $\mathrm{t}=0$. a $\mathrm{Gln}^{+}$transductants $(\bullet)$; total viable cells (a). b Transduction frequency

(where statistically significant numbers of transductants could be obtained). If the length of the delay in cell divisions were longer for some markers, then their relative transduction frequencies would be decreased more than the transduction frequencies of markers with shorter lags. However, if all markers displayed an equivalently long lag, the relative transduction frequencies would remain the same as they were at time zero. As can be seen from the data in Table 1, the relative transduction frequencies of the four markers did not change appreciably, confirming that all lagged for about the same length of time, about $3.5 \mathrm{~h}$.

\section{Discussion}

The data presented here show clearly that recombinants arising after $\mathrm{P} 1$-mediated transduction suppress cell division for 6 or more generation times while other cells in the culture - even those lysogenized by P1 - grow with little or no lag. Three issues warrant further discussion: the generality of this phenomenon, the direct applicability of the observation in the field of bacterial genetics, and the SOS response in enteric bacteria.

Our data are limited to recombinants arising from $\mathbf{P} 1$ mediated generalized transduction in $K$. aerogenes. Other data (Sandri and Berger 1980; Helling 1970), while collected for different purposes, strongly suggest that the effect is identical for P1 transduction in E. coli. Furthermore EbelTsipis et al. (1972) showed a similar though shorter delay

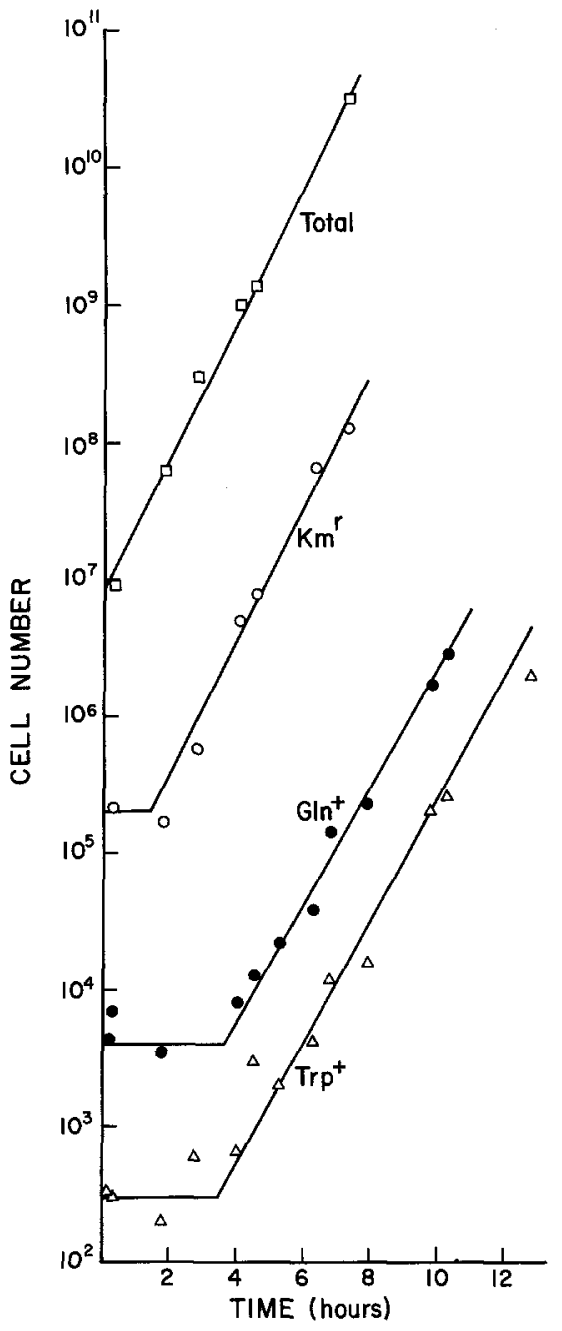

Fig. 5. Marker independence of cell-division lag. Phage P1 grown on the prototrophic strain MK 9000 was adsorbed to cells of strain MK9541 $\left(\mathrm{Gln}^{-}, \mathrm{Ilv}^{-}, \mathrm{Trp}^{-}, \mathrm{His}^{-}\right)$as described in Materials and Methods. The entire mixture was diluted to $1 \times 10^{7}$ cells $/ \mathrm{ml}$ and allowed to grow at $30^{\circ} \mathrm{C}$ with vigorous aeration and periodic dilution to maintain log phase growth. Samples were withdrawn periodically and titred for transductants (on minimal medium lacking glutamine, isoleucine, tryptophan, or histidine), for lysogens (on broth plates supplemented with kanamycin), and for total viable cells (on broth plates). All titres are expressed relative to the initial dilution. $\operatorname{Trp}^{+}(\Delta) ; \mathrm{Gln}^{+}(\bullet)$; total viable cells (ם); kanamycinresistant lysogens $(0)$

in cell division following P22-mediated transduction in $S$. typhimurium. Nor is this cell-division lag following recombination unique to transductionally derived recombinants. In his pioneering studies on $E$. coli fertility, Hayes (1957) showed that $\mathrm{Hfr}$ generated recombinants of $E$. coli fail to divide for 5 generation times when resuspended in broth. Therefore, we suggest that the cell-division lag we see following P1 mediated generalized transduction may be characteristic of all recA mediated recombination in the enteric bacteria. Tomizawa (1960) interpreted similar suppressions of cell division following Hfr crosses as the result of segregation of multiple copies of the genome. In particular, he did not report observing filaments at the frequencies we would predict. We argue that segregation is unlikely for our results because origin proximal markers ( $g \ln A$ and $i l v)$ show the same delay in replication as terminus proximal 
Table 1. Invariance of relative transduction frequencies

\begin{tabular}{lccc}
\hline Genetic marker & \multicolumn{3}{c}{ Relative transduction frequency } \\
\cline { 2 - 4 } & $0 \mathrm{~h}$ & $7 \mathrm{~h}$ & $11 \mathrm{~h}$ \\
\hline $\mathrm{gln}^{+}$ & $(1.0)$ & $(1.0)$ & $(1.0)$ \\
$\mathrm{ib}^{+}$ & 0.35 & 0.30 & 0.34 \\
$\mathrm{trp}^{+}$ & 0.08 & 0.08 & 0.09 \\
$\mathrm{his}^{+}$ & 0.02 & 0.03 & 0.05 \\
\hline
\end{tabular}

Transduction of strain MK9541 with P1 grown on strain MK9000 was performed as described in Materials and Methods. After adsorption, cells were diluted to $1.5 \times 10^{7} / \mathrm{ml}$ in broth and allowed to grow with periodic dilutions to keep the cell density between $1 \times 10^{7} / \mathrm{ml}$ and $1 \times 10^{9} / \mathrm{ml}$.

a Transduction frequencies were normalized to the $g / n^{+}$frequency (set at 1.0 ) which was $3 \times 10^{-5} \mathrm{Gln}^{+} /$viable cell at $\mathrm{t}=0$, $1.2 \times 10^{-6} \mathrm{Gln}^{+} /$viable cell at $\mathrm{t}=7 \mathrm{~h}$, and $8 \times 10^{-7} \mathrm{Gln}^{+} /$viable cell at $\mathrm{t}=10 \mathrm{~h}$

markers (his and trp). Since fast growing cells have significantly more copies of the origin region of the chromosome than of the terminus region (Cooper and Helmstetter 1968), a segregation model requires that origin proximal markers take longer to segregate than terminus markers, in contradiction to our data. Furthermore, the integrated DNA in Hfr recombinants has replicated at least twice by the time any increase in the number of cells displaying the recombinant phenotype is seen (cited in Wollman et al. 1956).

The fact that recombinants can be separated from nonrecombinants by physical methods as simple as sucrose gradients means that it is now feasible to use P1 mediated transduction to isolate transductants whose phenotype is scoreable but not selectable. One limiting feature of $\mathrm{P} 1 \mathrm{me}-$ diated transduction is the inability to isolate stable highfrequency-transducing variants of P1 (Wall and Harriman 1974). The ability to attain transduction frequencies in excess of $10^{-3}$ obviates the requirement for such a variant. In one pilot experiment, we plated about 1000 cells from the fast sedimenting peak of a 3 hour gradient like that shown in Fig. 3. In this experiment the recipient was wild type and the P1 lysate was grown on a $r h a^{-}$strain. Among the 1000 cells that grew on rhamnose indicator agar (MacConkey), one $r h a^{-}$colony was found. We assume such high frequencies will not be found when genes in less transducible regions of the chromosome (like the his-trp region) are used, but even so, the 100-fold increase in transduction frequency among cells from this region of the gradient may allow selection for recombinants in crosses where high reversion frequencies would otherwise obscure the results.

Finally, our observations regarding the effects of recombination on cell division need to be considered in light of our current models of the SOS response and the role of rec $A$ in this response to DNA damage. It is generally held that the basal level of recA protein expression is sufficient to mediate homologous recombination since prior induction of recA synthesis by U.V. irradiation does not increase recombination frequencies of average markers appreciably (Newman and Masters 1980). Our data suggest that it is inherent in the recombination event itself that the cells destined to become recombinants filament - a phenotype characteristic of the SOS response caused by U.V. irradiation or other DNA-damaging agents. If the filamentation is in fact part of the SOS response then each recombinant would appear in a cell with induced levels of recA product (as part of the SOS response). It is thought that small pieces of DNA resulting from degradation are the actual inducers of the SOS response. Such degradation must accompany P1 transductionally-mediated recombination since only about $10 \%$ of the DNA from the transducing particle actually becomes integrated into the chromosome (Sandri and Berger 1980). This model of recombination-induced SOS response would also allow a qualitative explanation of the lengths of the supression of cell division in three cases. The $90 \%$ of the average transducing DNA that fails to become part of the recipient chromosome is presumably degraded. This represents about $55 \times 10^{6} \mathrm{~d}$ of DNA in P1-mediated transduction. In P22-mediated transduction, about $20 \times 10^{6} \mathrm{~d}$ of DNA is thought to be degraded in transductants. P1 lysogeny results from an intramolecular recombination resulting in the loss (and presumed degradation) of about $7 \times 10^{6} \mathrm{~d}$ of DNA. The suppression of cell division in these three cases are about six, three, and two generations respectively, suggesting that the duration of the response may reflect the amount of degraded DNA. The possible causal linkages between recombination and induction of SOS functions can be tested using $E$. coli mutants that fail to filament: $\operatorname{lex} A$ in which SOS is uninducible and sulB in which SOS is normal except that cell division is not suppressed. Neither lexA nor sulB displays a $\operatorname{Rec}^{-}$phenotype, so induction of SOS is not essential for recombination. These mutants should settle the question of whether the suppression of cell division following recombination is mediated via the SOS system or by an independent mechanism.

In summary, our data show that a widely used technique, P1-mediated generalized transduction, has an unexpected consequence, suppression of cell division. This recombination-induced suppression of cell division at least superficially resembles that seen in other recombination systems, especially Hfr matings. This filamentation is potentially useful when enriching for transductants in a population.

Acknowledgements. We thank S.L. Streicher for helpful discussions and S. Allen and J. Adams for their careful reading of the manuscript. This work was supported by grants from the NIH-PHS (GM27111 and A115822) to R.A.B. who was recipient of an American Cancer Society Junior Faculty Research Award (JFRA-3).

\section{References}

Bachmann B, Low KB (1980) Linkage map of Escherichia coli K-12 Edition 6. Microbiol Rev 44:1-56

Bender RA, Janssen KA, Resnick AD, Blumenberg M, Foor F, Magasanik B (1977) Biochemical parameters of glutamine synthetase from Klebsiella aerogenes. J Bacteriol 129:1001-1009

Bender RA, Macaluso A, Magasanik B (1976) Glutamate dehydrogenase: genetic mapping and isolation of regulatory mutants of Klebsiella aerogenes. J Bacteriol 127:141-148

Bender RA, Magasanik B (1977) Autogenous regulation of the synthesis of glutamine synthetase in Klebsiella aerogenes. J Bacteriol 132:106-112

Cooper S, Helmstetter CE (1968) Chromosome replication and the division cycle of Escherichia coli $\mathrm{B} / \mathrm{r}$. J Mol Biol $31: 519-540$

Ebel-Tsipis J, Fox MS, Botstein D (1972) Generalized transduction by bacteriophage P22 in Salmonella typhimurium: II. mechanism of integration of transducing DNA. J Mol Biol 71:449 469

Goldberg RB, Magasanik B (1975) Gene order of the histidine utilization (hut) operons in Klebsiella aerogenes. J Bacteriol 122:1025-1031 
Goldberg RB, Bender RA, Streicher SL (1974) Direct selection for P1-sensitive mutants of enteric bacteria. $\mathrm{J}$ Bacteriol 118:810-814

Harding NE, Zyskind JW, Smith DW (1981) Replication origin region of Enterobacter aerogenes. J Supramolec Struct and Cell Biochem Supp 5:333

Harriman PD (1972) A single-burst analysis of the production of $P 1$ infectious and transducing particles. Virology 48:595-600

Hayes W (1957) The kinetics of the mating process in Escherichia coli. J Gen Microbiol 16:97-119

Helling RB (1967) The effect of arabinose-specific enzyme synthesis on recombination in the arabinose genes of Escherichia coli. Genetics 57:665-675

Ikeda H, Tomizawa J (1965) Transducing fragments in generalized transduction by phage P1 : I. Molecular origin of the fragments. J Mol Biol 14:85-109

Ikeda H, Tomizawa J (1965) Transducing fragments in generalized transduction by phage P1: II. Association of DNA and protein in the fragments. J Mol Biol 14:110-119

Lennox ES (1955) Transduction of linked genetic characters of the host by bacteriophage P1. Virology 1:190-206

MacPhee DG, Sutherland IW, Wilkinson JF (1969) Transduction in Klebsiella. Nature (London) $221: 475-476$

Newman BJ, Masters M (1980) The variation in frequency with which markers are transduced with phage $\mathrm{P} 1$ is primarily a result of discrimination during recombination. Mol Gen Genet $180: 585-589$
Sandri RM, Berger H (1980) Bacteriophage P1-mediated generalized transduction in Escherichia coli: fate of transduced DNA in $\mathrm{Rec}^{+}$and $\mathrm{RecA}^{-}$recipients. Virology 106:14-29

Sandri RM, Berger H (1980) Bacteriophage P1-mediated generalized transduction in Escherichia coli: structure of abortively transduced DNA. Virology 106:30-40

Streicher SL, Bender RA, Magasanik B (1975) Genetic control of glutamine synthetase in Klebsiella aerogenes. $\mathrm{J}$ Bacteriol $121: 320-331$

Tomizawa J (1960) Genetic structure of recombinant chromosome formed after mating in Escherichia coli K-12. Proc Natl Acad Sci USA 46:91-101

Tyler BM, Goldberg RB (1976) Transduction of chromosomal genes between enteric bacteria by bacteriophage P1. J Bacteriol 125:1105-1111

Wall JD, Harriman PD (1974) Phage P1 mutants with altered transducing abilities for Escherichia coli. Virology 59:532-544

Wollman E-L, Jacob F, Hayes W (1956) Conjugation and genetic recombination in Escherichia coli K-12. Cold Spring Harbor Symp Quant Biol 21:141-

Communicated by G. O'Donovan

Received November 13, 1982 